\title{
Income Shocks and Out-of-Pocket Health Care Spending: Implications for Single-Mother Families
}

\author{
Irina B. Grafova ${ }^{1}$ (D) Alan C. Monheit ${ }^{1} \cdot$ Rizie Kumar $^{2}$ \\ Accepted: 23 June 2021 / Published online: 6 July 2021 \\ (c) The Author(s), under exclusive licence to Springer Science+Business Media, LLC, part of Springer Nature 2021
}

\begin{abstract}
We examine how out-of-pocket health care spending by single-mother families responds to income losses. We use eleven two-year panels of the Medical Expenditure Panel Survey for the period 2004-2015 and apply the correlated random effects estimation approach. We categorize income in relation to the federal poverty line (FPL): poor or near-poor (less than 125\% of the FPL); low income (125 to $199 \%$ of the FPL); middle income (200 to 399\% of the FPL); and high income (400\% of the FPL or more). Income losses among high-income single-mother families lead a decline in out-of-pocket spending toward office-based care and emergency room care of $\$ 119-\$ 138$ and $\$ 30-\$ 60$, respectively. Among middle-income single-mother families, income losses lead to a $\$ 30$ decline in out-of-pocket spending toward family emergency room care and a $\$ 45-\$ 91$ decline in mother's out-of-pocket spending toward prescription medications. Further research should examine whether these declines compromise health status of single-mother family members.
\end{abstract}

Keywords Single mothers $\cdot$ Family health care spending $\cdot$ Out-of-pocket spending $\cdot$ Chronic conditions

\section{Introduction}

Since 1960, the percentage of children living with single mothers has increased by two and a half times. In 2019, single-mother families represented nearly $30 \%$ of all families with children (Census Bureau, 2019). Living with a single mother is the second most common family arrangement for children and has important implications for family welfare. Single-mother families face an increased risk of poverty and economic disadvantage (Barardehi et al., 2020). For example, in 2018 about $39 \%$ of single-mother families were in poverty compared to $8 \%$ of two-parent families (Semega

Irina B. Grafova

grafovib@sph.rutgers.edu

Alan C. Monheit

monheiac@sph.rutgers.edu

Rizie Kumar

riziekumar@gmail.com

1 Department of Health Behaviors, Society, and Policy, Rutgers University School of Public Health, 683 Hoes Lane West, Piscataway, NJ 08854, USA

2 Department of Sociology, University of Maryland, 2112 Parren J. Mitchell Art-Sociology Bldg, rm 3105, College Park, MD 20742, USA et al., 2020). Among workers, single mothers are the most likely to be in poverty, and are more likely than mothers in two-parent families to be uninsured (Henry J. Kaiser Family Foundation, 2020). Economic disadvantage and lack of health insurance lead to a higher rate of unmet healthcare need in single-mother families compared to two-parent families (Hayes \& Hartman, 2011; Irvin et al., 2018).

The Patient Protection and Affordable Care Act (ACA) enacted eleven years ago expanded health insurance coverage, prohibited plans from rescinding coverage, and from imposing annual and lifetime limits on health benefits. The ACA also introduced income-related premium and costsharing subsidies as well as required coverage for essential health benefits. Despite these provisions, the ACA failed to reduce the share of American families struggling to pay for health care out-of-pocket (Himmelstein et al., 2019; McCarthy-Alfano et al., 2019).

Most recently, the adverse economic impact of the COVID-19 outbreak has compromised family economic security and the ability of all families to pay for medical care. Prior to the COVID-19 outbreak, about half of adults reported that they or their family member had delayed or gone without care during the past year because of high outof-pocket costs (Kirzinger et al., 2019). As of August 2020, $42 \%$ of all families reported a job or income loss because of 
the pandemic (Parker et al., 2020) resulting in an additional $11 \%$ of adults reporting that they or their family member have problems paying for medical care due to the coronavirus outbreak. The share of families reporting problems paying for medical care since the beginning of the coronavirus outbreak is higher among families with lower incomes. For example, $19 \%$ of families with an annual income less than $\$ 39,800$ report problems paying for medical care since the coronavirus outbreak compared to $10 \%$ of families with an annual income between $\$ 39,800$ and $\$ 119,400$ (Parker et al., 2020).

Difficulties paying for health care may result in postponing or foregoing care. Overall, about $7 \%$ of adults reported forgoing care due to financial concerns during March through mid-July 2020 (Anderson et al., 2021). Among adults reporting missed prescription medications during this period, nearly a quarter cite financial reasons (Anderson et al., 2021).The effects of high out-of-pocket costs on both population health (Karaca-Mandic et al., 2014; Zan \& Scharff et al., 2018) and family financial well-being (Hackney et al., 2018; Shin \& Kim, 2018) have been a key concern among researchers and policymakers. Several studies find that families respond to income losses by decreasing outof-pocket spending (Ganong \& Noel, 2019; Karaca-Mandic et al., 2014). However, very few studies (Grafova et al., 2020b) are devoted specifically to how health care spending decisions in single-mother families are affected by income changes. Most of the existing literature devoted to singlemother families either finds that living in a single-mother family is associated with low income and high poverty rates, or links living in single-mother family to adverse physical and mental health outcomes (Bzostek \& Beck, 2011; Langton \& Berger, 2011).

One of the important findings from the relatively sparse literature devoted to how income losses affect single-mother family health care spending decisions is that single mothers are willing to absorb a decline in family healthcare spending in order to preserve the health care use of their children. Single mothers respond to an income loss by decreasing the share of total family health care spending allocated to themselves and increasing the share of total family health care spending allocated to their children. For example, a decline in income from high-income status (income at least four times the federal poverty line) to near-poor income status (incomes between $100 \%$ to less than $125 \%$ of the federal poverty line) for such families yields a statistically significant increase of 12 percentage points in the share of family spending for total ambulatory care going to children, and a 10 percentage point increase in the share of family spending for office-based physician care going to children (Monheit et al., 2020). A decline from middle-income status (incomes between 200 to $399 \%$ of the federal poverty line) to nearpoor economic status (incomes between 100\% to less than
$125 \%$ of the federal poverty line) results in a 10 percentage point increase in children's shares of family health spending for all ambulatory care services, and a 7 percentage point increase in children's chare of family prescription drug spending.

This literature also finds that maternal health is an important factor shaping family health care spending decisions (Valluri et al., 2015). The share of total healthcare spending going to children is lower in single-mother families where mothers are in fair or poor health and are diagnosed with chronic conditions, such as arthritis, asthma, or chronic heart disease, than in families where single mothers are in better health (Monheit et al., 2020). This is consistent with another finding that parental functional or sensory limitation is associated with an additional \$264-\$333 in out-of-pocket spending toward parental health care (Karaca-Mandic et al., 2013).

\section{Focus of This Study}

To summarize, the existing literature on single mothers' healthcare spending decision is sparse. Our study contributes to this literature in several major ways. First, unlike previous studies (Grafova et al., 2020a; Monheit et al., 2020), we concentrate on how out-of-pocket rather than total health care spending is affected by income losses. Thus, we specifically focus on what single mothers pay in the form of deductibles, copays, and coinsurance disregarding the health care costs covered by any health insurance they may hold. Second, we examine out-of-pocket health care spending among broad service categories, including office-based visits, emergency department care, and prescription medications. Previous research on the impact of socioeconomic status on out-ofpocket spending by service categories considered all families with children rather than single-mother families who may be particularly vulnerable to income losses (Karaca-Mandic et al., 2013). Third, we recognize that maternal health can potentially affect not only out-of-pocket health care spending by mothers but also can shape their income trajectory. Thus, when examining out-of-pocket spending by single mothers, we stratify our analysis by their health status and examine out-of-pocket spending by single mothers with and without diagnosed chronic conditions separately. Finally, we use a rigorous methodological approach that provides estimates of the within-family change in out-of-pocket family health care spending in response to an income change over a two-year observation period. As described in the Empirical Approach section below, we apply the correlated random effects estimation approach. This method adjusts for unobserved heterogeneity in family characteristics that is possibly correlated with our explanatory variables. Failure to address such unobserved heterogeneity could potentially 
bias our estimates of how the family's out-of-pocket spending responds to income losses (Papke \& Wooldridge, 2008).

To implement our analysis, we use eleven two-year panels of the Medical Expenditure Panel Survey (MEPS) for the period 2004 to 2015 We categorize family income ${ }^{1}$ in relation to the federal poverty line (FPL) using the following income classes: poor or near-poor (less than $125 \%$ of the FPL); low income (125 to $199 \%$ of the FPL); middle income (200 to $399 \%$ of the FPL), with high income (400\% of the FPL or more). We then examine how an income shock which changes a single-mother family's income position affects the family's out-of-pocket spending.

Finally, during our study period, initial provisions of the Affordable Care Act (ACA) were implemented beginning September 2010 with many critical provisions regarding coverage implemented beginning January 1, 2014. The 2010 implementation may have affected out-of-pocket spending through the removal of lifetime limits on the dollar value of coverage, and through expansion of young adult dependent coverage. The 2014 implementation may have had a more significant impact on such spending through several provisions including the establishment of the ACA's health insurance exchanges which provided access to health plans covering up to $90 \%$ of benefit costs; the ACA's health insurance mandates for individuals and employers; it's cost-sharing subsidies for low-income individuals; the elimination of preexisting condition constraints; and in participating states, the expansion of Medicaid to individuals with incomes less than $138 \%$ of the federal poverty line. As noted earlier, studies by Himmelstein et al. (2019) and McCarthy-Alfano et al. (2019) indicate that the ACA failed to reduce the share of American families struggling to pay for health care out-of-pocket. In our empirical work, we revisit this issue by considering whether implementation of the ACA had an impact of the out-of-pocket spending by single-mother families.

\footnotetext{
1 The family income measure used in the analysis consists of annual earnings from wages, salaries, bonuses, tips, commissions; business and farm gains and losses; unemployment and workman's compensation; interest and dividends; alimony, child support, and other private cash transfers; private pensions, IRA withdrawals, social security, and veterans payments; supplemental security income and cash welfare payments from public assistance, Aid to Families with Dependent Children, and Aid to Dependent Children; gains or losses from estates, trusts, partnerships, $\mathrm{S}$ corporations, rent, and royalties; and a small amount of "other" income. Family income excluded tax refunds and capital gains.
}

\section{Methods}

\section{Data}

This study uses data from the Medical Expenditure Panel Survey (MEPS). The MEPS is a nationally representative series of overlapping two-year panel data sets. We pool data from eleven of these panels: from the 2004-2005 panel to the 2014-2015 panel. Respondents provide data on health status, health care spending and utilization, health insurance coverage, income, and employment status of the respondents themselves and their family members. Follow-back surveys of physicians, hospitals, and pharmacies identified by respondents provide more complete information on spending and utilization.

To obtain family out-of-pocket spending, we calculated out-of-pocket health care spending for each individual family member and then aggregated these data to obtain a family-level measure of such spending. For families with health insurance, the family's out-of-pocket spending for medical care reflects its responsibility for deductibles, coinsurance, copayments and any spending in excess of the plan's annual or lifetime limits on insurance reimbursements. For uninsured, out-of-pocket spending will reflect the total spending for medical care services incurred by the family. Outof-pocket health care spending variables were deflated by the Personal Health Care Expenditure (PHCE) price index component of the National Health Expenditure Accounts (AHRQ, 2016).

\section{Sample}

We impose several sample restrictions. We require that all family members are present in the data for both years of a two-year panel. We excluded families with births during the two-year period since such families may have experienced a one-time spike in their health care spending associated with pre-natal care and childbirth. We exclude families with individuals ages 65 years or older from the sample. We exclude families with children ages 19 or older and restrict the sample to single-mother families. Finally, we drop families with missing data on important family economic and demographic characteristics. These exclusions resulted in a sample of 4,349 single-mother families.

\section{Empirical Approach}

To assess how single-mother families' out-of-pocket health care spending responds to an income shock, we estimate two-part expenditure models and use the correlated random effects (CRE) method to control for time-invariant, unobserved heterogeneity across family units (Chamberlain, 
1980; Mundlak, 1978; Wooldridge et al., , 2019). The CRE framework also produces estimates of the within-family change in out-of-pocket spending in response to income changes over the two-year MEPS observation periods (Papke $\&$ Wooldridge, 2008). The CRE approach imposes a strong assumption regarding the dependence between the unobserved family effects and the observed explanatory variables. Specifically, the dependence between the unobserved effect and the observed explanatory variables is assumed to follow the conditional normal distribution with a linear expectation and constant variance (Chamberlain, 1980; Mundlak, 1978).

In the first part of the two-part model, we apply a probit regression to estimate the probability that the family incurs out-of-pocket health care spending. In the second part of the model, we apply a generalized linear expenditure model (GLM) to estimate the level of out-of-pocket health care spending conditional on positive family out-of-pocket health care spending. The GLM model requires a link function (such as a logarithmic link) to relate the conditional mean expenditure to the vector of explanatory variables, and also requires specification of a variance function for the conditional mean (such as the Poisson, Gamma, or Inverse Gaussian distributions). We used the Tukey-Pregibon procedure to validate our selection of the logarithmic link function and applied the modified Park test (Park, 1966) to select the appropriate distribution function. We applied MEPS family weight to our estimated model and adjust standard errors for the clustered sampling design of the MEPS.

In our empirical models, we controlled for various individual and family-level characteristics, including mother's age, education, race, and ethnicity, whether mother or any of children was in fair/poor health (a full list of variables appear as notes to Tables 3, 4,5). This health status measure was based on mother's self-assessed reports of whether they or their children were in excellent, very good, good, poor or fair health. As described below, we also included variables indicating whether a mother had a MEPS priority health condition. Finally, we included the number of children in the family, the family's region of residence, and year-specific dummy variables.

We assess the impact of changes in a single-mother family's income position and in other aspects of its economic status on family out-of-pocket spending over the two-year MEPS observation periods. To do so, we estimated the above models and used measures of family income, employment status, and health insurance status in each panel year. As described above, we categorize family income in relation to the federal poverty line (FPL) and we examine how changes in the income category a family belongs to affect family out-of-pocket spending. We used differences in predicted average marginal effects of the change between income categories on family out-of-pocket spending to estimate the impact of an income shock. ${ }^{2}$

We also characterize mother's employment status during each year of the two-year panels with a set of dummy variables. These variables indicate whether a single-mother was continuously employed during the year, lost employment during the year, gained employment during the year, or was continuously without employment during the year (the reference category). These variables are not entirely mutually exclusive since multiple job transitions are possible throughout the year.

Since previous research indicates that not only the presence of health insurance (Abramowitz, 2020; Golberstein \& Gonzales, 2015) but also the type of health insurance coverage (Kwon et al., 2018; Shaefer et al., 2011) may affect out-of-pocket spending, we include detailed indicators of family health insurance coverage. These variables indicate whether all family members are insured for the entire year by public health insurance; whether all family members are insured for the entire year by private health insurance; whether all family members are insured for the entire year by both public and private health insurance; whether some family members are uninsured for at least part of the year and other family members are covered by public health insurance; whether some family members are uninsured for at least part of the year and other family members are covered by private health insurance; whether some family members are uninsured for part of the year and other family members are covered by both public and private health insurance; and whether everyone in the family is uninsured for the entire year (reference category). As with family income, we use differences in the predicted marginal effects for each insurance category to estimate the impact of a change in health insurance status. Finally, we included year-specific dummy variables for the years 2010 and beyond, to account for the impact that the ACA implementation may have had on the out-of-pocket spending by single-mother families pre- and post- the 2010 and 2014 implementation years. Also, all our regressions are adjusted for maternal race and ethnicity, maternal educational attainment, mother's age at the year one of the panel, age of the youngest child at the first year of the panel, number of children in the family, indicators

\footnotetext{
${ }^{2}$ We focus on the poverty-level measures for two reasons. First, use of these indicators capture any non-linearities in the relationship between income and out-of-pocket health care expenditures. Next our aim is to examine the impact of substantive changes in income experienced by single-mother families which are captured by movements across the poverty-level categories over time. For example, moving from the income threshold of four times the FPL in 2015 for a family of three to the threshold for three times the FPL represents an income loss of over $\$ 25,000(\$ 75,360-\$ 50,240)$. Such a dramatic shift is not likely to be captured using a continuous measure of income.
} 
for whether there any parents and any children in fair/poor health in the family, and region of residence.

Using this approach, we first analyzed outcomes reflecting total family out-of-pocket health care spending and family out-of-pocket spending for three broad service categories: office-based visits, emergency department care, and prescription medications. Note that over-the-counter remedies are not included in our measure of out-of-pocket health care spending as these expenditures are not captured by MEPS. To explore the impact of economic shocks across single-mother family members, we repeated the analysis for mothers' and children's out-of-pocket spending outcomes. To explore the role of mother's health in their out-of-pocket health care spending decisions, we stratified the analysis of maternal out-of-pocket spending by mother's health status based on whether mothers had any of the Agency for Health Care Research and Quality's priority health conditions. These conditions are: hypertension, heart disease, high cholesterol, emphysema, diabetes, arthritis, asthma, and stroke.

\section{Results}

In Table 1, we present selected characteristics of our single-mother sample based upon data from the first year of each MEPS panel. We find that over $40 \%$ of single-mother families are poor or near-poor. Nearly $60 \%$ of single mothers are continuously employed throughout the entire year. About $16 \%$ of single mothers report having lost employment some time during a year with $11 \%$ reporting having gained employment during a year. Single-mother families are likely to lack health insurance coverage or to be covered by public health insurance. Nearly $40 \%$ of single-mother families report that someone in their family lacked health insurance at some point during a year. Only a quarter of single-mother families report having all members continuously covered by private health insurance. About $22 \%$ of single-mother families have all members insured by public insurance throughout the entire year. About 54\% of single mothers in the sample are diagnosed with a chronic condition. Table 1 shows that chronic conditions diagnosis is associated with lower likelihood of being employed all year long, greater likelihood of being without employment all year long, and a greater likelihood that all family members are covered by public insurance for the entire year.

Table 2 reveals that $88 \%$ of single-mother families incur out-of-pocket health care spending during the first year of each MEPS panel. Mean total family out-of-pocket health care spending among families incurring expenditures is $\$ 1,107$. Mean out-of-pocket spending is nearly three times as large as median out-of-pocket spending of $\$ 373$, indicating that the out-of-pocket expenditure data are highly skewed. About $62 \%$ of single-mother families had out-of-pocket spending for office-based visits, about $12 \%$ had out-ofpocket spending for emergency room care, and about $76 \%$ of single-mother families incurred out-of-pocket spending on prescription medications. Table 2 also shows that while median out-of-pocket spending for office-based visits and prescription medications are lower among single-mothers without chronic health conditions than among single-mothers having chronic condition, it is the opposite for median out-of-pocket spending for emergency room care.

About 33\% of families in our samples experienced an income shock sizable enough to change the family's income classification. Tables 3, 4, 5 display the average marginal effects of income shocks on single-mother family out-ofpocket spending derived from our expenditure models. Note that following the empirical approach described above, each regression accounts for not only changes in income category but also changes in employment status and health insurance coverage. Table 3 focuses on total out-of-pocket family spending and on three components of such spending: office-based visits, emergency room services, and prescription medications.

\section{Changes in Total Family Out-of-Pocket Spending}

Table 3 reveals that for single-mother families, a decline from middle-income or high-income to low-income status results in a decrease in expected out-of-pocket spending of about $\$ 419$ and $\$ 446$, respectively. A decline from middleincome or high-income to poor or near-poor income status in single-mother families leads to a decrease in expected outof-pocket spending of about $\$ 266$ and $\$ 293$, respectively. By contrast, a decline from high-income to middle-income status and a decline from low-income to poor or near-poor income status in single-mother families have no statistically significant impact on total family out-of-pocket spending.

\section{Changes in Out-of-Pocket Spending by Service Category}

Table 3 also reports the impact of an income loss on particular types of out-of-pocket spending. A decline in income among high-income single-mother families to a lower income category leads to an average decline of \$119-\$138 in out-of-pocket spending toward office-based visits and an average decline of \$30-\$60 toward emergency room care. A decline in income among middle-income single-mother families to a lower income category leads to an average decline of about $\$ 30$ toward emergency room care. Additionally, middle-income families that lost income and became low-income families decrease their out-of-pocket spending toward prescription medication on average by $\$ 106$. By contrast, a decline in income from low-income to poor or near-poor family income and a decline in income from 
Table 1 Sample descriptive statistics

\begin{tabular}{|c|c|c|c|}
\hline Variables & $\begin{array}{l}\text { Single-mother families, } \\
\mathrm{N}=4,349\end{array}$ & $\begin{array}{l}\text { Without chronic condition } \\
(\mathrm{N}=2,400)\end{array}$ & $\begin{array}{l}\text { Single mothers with } \\
\text { chronic condition } \\
(\mathrm{N}=1,949)\end{array}$ \\
\hline \multicolumn{4}{|l|}{ Income } \\
\hline Poor or near poor: $<125 \%$ poverty line, $\%$ & 42.9 & $44.8 * *$ & 40.7 \\
\hline Low income: $[125 ; 200) \%$ poverty line, $\%$ & 21.3 & $20.0 *$ & 22.8 \\
\hline Middle income: $[200 ; 400) \%$ poverty line, $\%$ & 25.0 & 24.4 & 25.8 \\
\hline High income: $>=400 \%$ poverty line, $\%$ & 10.7 & 10.7 & 10.7 \\
\hline \multicolumn{4}{|l|}{ Maternal employment } \\
\hline Not employed all year long, $\%$ & 17.3 & $12.7 * * *$ & 22.7 \\
\hline Employed all year long, \% & 60.1 & $64.2 * * *$ & 55.4 \\
\hline Gained employment during a year, $\%$ & 10.9 & 11.4 & 10.4 \\
\hline Lost employment during a year, $\%$ & 15.6 & 15.5 & 15.8 \\
\hline \multicolumn{4}{|l|}{ Health insurance } \\
\hline \multicolumn{4}{|l|}{ All family members are insured for the entire year by } \\
\hline Public health insurance, $\%$ & 21.9 & $19.1 * * *$ & 25.0 \\
\hline Private health insurance, $\%$ & 27.6 & 26.5 & 28.9 \\
\hline Both public and private health insurance, $\%$ & 8.5 & 8.4 & 8.7 \\
\hline \multicolumn{4}{|c|}{ Some family members are uninsured for part of the year and other family members are covered by } \\
\hline Public health insurance, $\%$ & 21.1 & $24.1 * * *$ & 17.7 \\
\hline Private health insurance, $\%$ & 9.0 & 9.3 & 8.7 \\
\hline Both private and public health insurance, $\%$ & 9.0 & 9.2 & 8.7 \\
\hline $\begin{array}{l}\text { Everyone in the family is not insured for the entire } \\
\text { year, } \%\end{array}$ & 2.9 & $3.4^{*}$ & 2.3 \\
\hline \multicolumn{4}{|l|}{ Maternal race and ethnicity } \\
\hline White non-Hispanic, $\%$ & 48.5 & $46.7 *$ & 50.5 \\
\hline Black non-Hispanic, \% 6.2230 .11 & 29.6 & 29.3 & 30.0 \\
\hline Other race, non-Hispanic, \% & 4.5 & $3.8^{*}$ & 5.2 \\
\hline Hispanic, $\%$ & 17.4 & $20.2 * * *$ & 14.3 \\
\hline \multicolumn{4}{|l|}{ Maternal educational attainment } \\
\hline Less than high school, $\%$ & 15.3 & 15.8 & 14.7 \\
\hline High school diploma or GED, $\%$ & 31.4 & 32.7 & 29.8 \\
\hline Some college, $\%$ & 33.4 & $31.5 * *$ & 35.5 \\
\hline College degree, $\%$ & 20.0 & 20.0 & 19.9 \\
\hline Mother's age, years & 36.12 & $34.12 * * *$ & 38.45 \\
\hline Age of the youngest child, years & 8.22 & $7.29 * * *$ & 9.29 \\
\hline Number of children in the family & 1.68 & $1.71 *$ & 1.64 \\
\hline Mother in fair or poor health, $\%$ & 22.6 & $12.7 * * *$ & 34.1 \\
\hline Any child in fair or poor health, $\%$ & 9.6 & $7.0^{* * *}$ & 12.6 \\
\hline \multicolumn{4}{|l|}{ Region of residence } \\
\hline Midwest, \% & 22.2 & 21.2 & 23.3 \\
\hline Northeast, \% & 17.2 & 16.6 & 17.9 \\
\hline West, $\%$ & 18.8 & $20.6 * * *$ & 16.6 \\
\hline South, \% & 41.9 & 41.7 & 42.2 \\
\hline Mothers without chronic conditions, $\%$ & 53.72 & & \\
\hline
\end{tabular}

The analytic sample used pools eleven two-year panels of the Medical Expenditure Panel Survey (MEPS) for the period 2004-2015. This table describes sample characteristics based on year one of each panel. Sample descriptive statistics are calculated using MEPS family weights, statistical significance tests use standard errors adjusted for the clustered sampling design of the MEPS

Statistically significantly different from families where mothers have chronic condition at * $p=0.1, * * p=0.05, * * * p=0.01$ 
Table 2 Out-of-pocket spending (OOP) by single-mother families: descriptive statistics

\begin{tabular}{|c|c|}
\hline \multirow{2}{*}{$\begin{array}{l}\text { Out-of-pocket spend- } \\
\text { ing }\end{array}$} & Single-mother families \\
\hline & Median OOP, \$ \\
\hline
\end{tabular}

\begin{tabular}{lcrr}
\hline All single mothers $(\mathrm{N}=4,349)$ & & \\
Total & 88.0 & 1106.52 & 373.05 \\
Office-based visits & 62.4 & 381.44 & 129.31 \\
Emergency room & 12.4 & 349.50 & 126.46 \\
$\begin{array}{l}\text { Prescription medi- } \\
\quad \text { cation }\end{array}$ & 75.7 & 359.52 & 86.16
\end{tabular}

Single mothers without chronic condition $(\mathrm{N}=2,400)$

$\begin{array}{lllr}\text { Total } & 83.5 & 838.41 & 304.88 \\ \text { Office-based visits } & 59.0 & 276.17 & 110.49 \\ \text { Emergency room } & 10.9 & 341.58 & 142.25 \\ \text { Prescription medi- } & 67.4 & 205.79 & 58.78 \\ \quad & & & \end{array}$

Single mothers with chronic condition $(\mathrm{N}=1,949)$

\begin{tabular}{lrrr} 
Total & 93.2 & 1385.35 & 468.94 \\
Office-based visits & 66.4 & 489.96 & 146.48 \\
Emergency room & 14.2 & 356.52 & 122.06 \\
$\begin{array}{l}\text { Prescription medi- } \\
\quad \text { cation }\end{array}$ & 85.4 & 500.33 & 124.97 \\
\hline
\end{tabular}

The analytic sample used pools eleven two-year panels of the Medical Expenditure Panel Survey (MEPS) for the period 2004-2015. This table describes sample characteristics based on year one of each panel. The mean and median OOP are calculated conditional on having any OOP. Sample descriptive statistics are calculated using MEPS family weights

high-income to middle-income leads to an increase in prescription medication out-of-pocket spending of \$64-\$70.

\section{Changes in Mothers' and Children's Out-of-Pocket Spending}

Next, we examine how an income loss affects mothers' and children's out-of-pocket spending. Table 4 indicates that most of the decline in out-of-pocket spending is borne by mothers. In high-income families experiencing income losses, single mothers decrease out-of-pocket spending for their own emergency room care by $\$ 19-\$ 37$ while the decline in out-of-pocket spending toward children's emergency room care is not statistically significant. Similarly, in middle-income families experiencing income losses, mothers decrease their out-of-pocket spending toward their own prescription medications by $\$ 45-\$ 90$ leaving out-of-pocket spending toward children's prescription medication nearly the same.

In a few cases we find that out-of-pocket spending on behalf of children's health care declines despite single mothers bearing most of the family's reduction in out-of-pocket spending. In high-income families experiencing an income loss, mother's out-of-pocket spending toward office-based visits decreases by about $\$ 45-\$ 57$ while children's out-ofpocket spending toward office-based visits decreases by about \$27-\$42. Additionally, the decline in out-of-pocket spending for emergency room care for middle-income families becoming low income is split nearly equally between mothers and children.

\section{Maternal Health and Mothers' Out-of-Pocket Spending Decisions}

Table 5 reveals how income losses affect the health care spending decision of mothers with and without diagnosed chronic conditions. It appears that declines in maternal out-of-pocket spending for office-based visits and emergency room care observed in Table 4 are primarily driven by healthier mothers with no diagnosed chronic conditions. For instance, in high-income families that become middleincome families, mothers without diagnosed chronic conditions reduce their out-of-pocket spending toward officebased visits and emergency room care by $\$ 69$ and $\$ 24$, respectively. By contrast, mothers with diagnosed chronic conditions in such families have no statistically significant changes in their out-of-pocket spending for office-based visits and emergency room care.

We also find that the increases in maternal out-of-pocket spending toward prescription medications observed in Table 4 are primarily driven by mothers with diagnosed chronic conditions. Single mothers with chronic conditions in high- or low-income families who lose income and become poor or near poor increase their out-of-pocket spending toward prescription medications by $\$ 80-\$ 110$. Similarly, single mothers with chronic conditions in highincome families who lose income and become middle income increase out-of-pocket spending on prescription medications by $\$ 162$. By contrast, changes in out-of-pocket spending for prescription medications for mothers without chronic conditions are drastically different. Single mothers with no diagnosed chronic conditions who lose income and become low income decrease their out-of-pocket spending for their prescription medications by $\$ 30-\$ 51$.

\section{The Affordable Care Act and Out-of-Pocket Spending}

As noted above, we tested for the potential effect of the ACA on out-of-pocket spending over the study time period by including a series of year-specific dummy variables (results available upon request). We examined the significance of the 2014 and 2015 year dummy variables relative to 2013 year dummy variable. We found no statistically significant difference in out-of-pocket costs in 2014 and 2015 relative to out-of-pocket costs in 2013. Additionally, we examined the significance of 2010-2015 year dummy variables relative 
Table 3 Expected average marginal effects of income loss on single-mother family out-of-pocket spending

\begin{tabular}{|c|c|c|c|c|c|}
\hline Income shock: change from & Total out-of-pocket & Total mothers OOP & Office-based visits & Emergency room & Prescription medication \\
\hline $\begin{array}{l}\text { Low income to poor or near } \\
\text { poor income }\end{array}$ & $153.51(141.21)$ & $60.41(63.23)$ & $0.11(54.63)$ & $-1.62(13.39)$ & $\mathbf{7 0 . 3 3} * *(\mathbf{2 8 . 0 4})$ \\
\hline $\begin{array}{l}\text { Middle income to poor or } \\
\text { near- poor income }\end{array}$ & $-292.87 * *(137.36)$ & $-176.66 * *(82.04)$ & $19.33(54.53)$ & $-30.35 *(16.25)$ & $-35.93(31.6)$ \\
\hline Middle income to low income & $-446.38 * *(206.87)$ & $-237.07 * * *(82.36)$ & $19.22(39.71)$ & $-28.73 *(14.82)$ & $-106.27 *(33.84)$ \\
\hline $\begin{array}{l}\text { High income to poor or near- } \\
\text { poor income }\end{array}$ & $-266.42 *(149.5)$ & $-135.38 *(81.36)$ & $-119.29 *(62.26)$ & $-59.89 * * *(20.02)$ & $28.3(38.25)$ \\
\hline High income to low income & $-419.93 * *(199.85)$ & $-195.79 * *(87.98)$ & $-119.4 *(67.15)$ & $-58.27 * * *(19.87)$ & $-42.04(41.24)$ \\
\hline $\begin{array}{l}\text { High income to middle } \\
\text { income }\end{array}$ & $26.44(116.22)$ & $41.28(75.51)$ & $-138.62 * *(63.49)$ & $-29.54 *(16.51)$ & $64.23 *(33.97)$ \\
\hline Sample size & 4,349 & 4,349 & 4,349 & 4,349 & 4,349 \\
\hline
\end{tabular}

Bolded estimates are significant at $10 \%$ significance level

Full model estimation results are available upon request. Standard errors in parentheses. Other regressors include maternal employment (mother not employed all year long (reference category), mother employed all year long, mother gained employment during a year, mother lost employment during a year), health insurance coverage (all family members are insured for the entire year by public health insurance; all family members are insured for the entire year by private health insurance, all family members are insured for the entire year by both public and private health insurance, some family members are uninsured for part of the year and other family members are covered by public health insurance, some family members are uninsured for part of the year and other family members are covered by private health insurance, some family members are uninsured for part of the year and other family members are covered by both public and private health insurance, everyone in the family is not insured for the entire year (reference category)), maternal race and ethnicity (Black non-Hispanic, white non-Hispanic (reference category), other race non-Hispanic, Hispanic), maternal educational attainment (less than high school, high school diploma or GED (reference category), some college, and college degree), mother's age at the year one of the panel, age of the youngest child at the first year of the panel, number of children in the family, indicators for whether there any parents and any children in fair/poor health in the family, region of residence (Midwest, Northeast, West, South (reference category). Regressions also include year dummies and within family time averages of income, employment, and health insurance variables for the Mundlak CRE estimation procedure. All models apply MEPS family weights and adjust standard errors for the clustered sampling design of the MEPS

$* p=.10 ; * * p=.05 ; * * * p=.01$

Table 4 Expected average marginal effects of income loss on out-of-pocket spending in single-mother families: mothers' and children's out-ofpocket spending

\begin{tabular}{|c|c|c|c|c|c|c|}
\hline \multirow{2}{*}{$\begin{array}{l}\text { Income shock: change } \\
\text { from }\end{array}$} & \multicolumn{2}{|l|}{ Office-based visits } & \multicolumn{2}{|l|}{ Emergency room } & \multicolumn{2}{|c|}{ Prescription medication } \\
\hline & Mothers & Children & Mothers & Children & Mothers & Children \\
\hline $\begin{array}{l}\text { Low income to poor or } \\
\text { near- poor income }\end{array}$ & $-11.74(19.5)$ & $10.17(15.39)$ & $6.41(8.19)$ & $3.36(10.52)$ & $45.64 *(24.06)$ & $20.98 * *(9.96)$ \\
\hline $\begin{array}{l}\text { Middle income to poor or } \\
\text { near- poor income }\end{array}$ & $-7.33(22.66)$ & $-4.81(16.08)$ & $-11.58(9.54)$ & $-14.88(11.7)$ & $-45.32 *(26.68)$ & $11.58(10.49)$ \\
\hline $\begin{array}{l}\text { Middle income to low } \\
\text { income }\end{array}$ & $4.42(22.12)$ & - $14.98(11.66)$ & $-17.99 * *(8.81)$ & $-18.24 *(9.42)$ & $-90.95 * * *(26.82)$ & $-9.40(9.36)$ \\
\hline $\begin{array}{l}\text { High income to poor or } \\
\text { near- poor income }\end{array}$ & $-56.43 * *(24.49)$ & $-32.23(20.93)$ & $-30.85 * *(12.71)$ & - $13.98(13.00)$ & $16.24(32.3)$ & $9.50(15.68)$ \\
\hline $\begin{array}{l}\text { High income to low } \\
\text { income }\end{array}$ & $-44.68 *(26.49)$ & $-42.40 * *(19.36)$ & $-37.26 * * *(13.51)$ & $-17.34(12.61)$ & $-29.39(34.45)$ & $-11.47(13.86)$ \\
\hline $\begin{array}{l}\text { High income to middle } \\
\text { income }\end{array}$ & $-49.1 *(25.28)$ & $-27.42 *(15.7)$ & $-19.27 *(11.75)$ & $0.90(9.63)$ & $61.56 * *(30.84)$ & $-2.07(10.04)$ \\
\hline Sample size & 4,349 & 4,349 & 4,349 & 4,349 & 4,349 & 4,349 \\
\hline
\end{tabular}

Bolded estimates are significant at $10 \%$ significance level

See noted in Table 3 for the regressors included in our estimation

to 2009 year dummy variable. The $2010-2013$ year dummy variables were not statistically different from the year 2009 dummy variable indicating no statistically significant change in the out-of-pocket spending trend during 2009-2013 time period. The year 2014-2015 dummy variables were statistically different from the year 2009 dummy variable indicating statistically significant lower out-of-pocket costs in 2014 and 2015 relative to 2009 . Specifically, the results indicated 
Table 5 Expected average marginal effects of income loss out-of-pocket on single mothers' out-of-pocket spending: the role of chronic conditions

\begin{tabular}{|c|c|c|c|c|c|c|}
\hline \multirow{3}{*}{$\begin{array}{l}\text { Income shock: } \\
\text { change from }\end{array}$} & \multicolumn{2}{|l|}{ Office-based visits } & \multicolumn{2}{|l|}{ Emergency room } & \multicolumn{2}{|c|}{ Prescription medication } \\
\hline & \multicolumn{6}{|l|}{ Single mothers } \\
\hline & $\begin{array}{l}\text { Without chronic } \\
\text { condition }\end{array}$ & $\begin{array}{l}\text { With chronic } \\
\text { conditions }\end{array}$ & $\begin{array}{l}\text { Without chronic } \\
\text { condition }\end{array}$ & $\begin{array}{l}\text { With chronic } \\
\text { conditions }\end{array}$ & $\begin{array}{l}\text { Without chronic } \\
\text { condition }\end{array}$ & $\begin{array}{l}\text { With chronic } \\
\text { conditions }\end{array}$ \\
\hline $\begin{array}{l}\text { Low income to } \\
\text { poor or near- } \\
\text { poor income }\end{array}$ & $-37.94(18.15)^{* *}$ & $31.1(30.62)$ & $9.28(10.52)$ & $16.31(14.64)$ & $17.45(16.39)$ & $\begin{array}{l}80.2 * \\
(48.71)\end{array}$ \\
\hline $\begin{array}{l}\text { Middle income to } \\
\text { poo or near-poor } \\
\text { income }\end{array}$ & $-0.82(22.14)$ & $-0.69(34.97)$ & $-5.81(11.23)$ & $-2.83(15.54)$ & $-12.57(18.86)$ & $-52.08(44.33)$ \\
\hline $\begin{array}{l}\text { Middle income to } \\
\text { low income }\end{array}$ & $37.12(22.6)^{*}$ & $-31.78(29.28)$ & $-15.09(12.94)$ & - $19.14(13.74)$ & $-30.02 *(15.71)$ & $\begin{array}{l}-132.28 * * * \\
(49.15)\end{array}$ \\
\hline $\begin{array}{l}\text { High income to } \\
\text { poor or near- } \\
\text { poor income }\end{array}$ & $\begin{array}{l}-69.62 \\
(26.05) * * *\end{array}$ & $-12.86(38.11)$ & $-30.05(16.18)^{*}$ & $-14.69(18.37)$ & $-33.41(24.87)$ & $110.03 * * *(56.03)$ \\
\hline $\begin{array}{l}\text { High income to } \\
\text { low income }\end{array}$ & $-31.68(26.89)$ & $-43.96(38.98)$ & $-39.33(20.21)^{*}$ & $-31(19.19)$ & $-50.86 * *(23.12)$ & $29.83(57.45)$ \\
\hline $\begin{array}{l}\text { High income to } \\
\text { middle income }\end{array}$ & $-68.8(24.69)^{* * * *}$ & $-12.17(36.02)$ & $-24.24(14.82)^{*}$ & $-11.86(17.07)$ & $-20.84(17.66)$ & $162.11 * * *(52.04)$ \\
\hline Sample size & 2,400 & 1,949 & 2,400 & 1,949 & 2,400 & 1,949 \\
\hline
\end{tabular}

Bolded estimates are significant at $10 \%$ significance level

See noted to Table 3 for the regressors included in our estimation

that total family out-of-pocket spending were on average $\$ 203$ ( -value $=0.08$ ) lower in 2014 compared to 2009 . Total family out-of-pocket spending was on average $\$ 352$ ( $\mathrm{p}$-value $=0.03$ ) lower in 2015 compared to 2009. Thus, we did not obtain consistent findings that ACA implementation was associated with lower out-of-pocket spending. This at least in part could be due to our limited ability to fully capture the effect of the full implementation of the ACA beginning January 1, 2014 since we have only two years of post-ACA implementation data 2014 and 2015.

\section{Discussion}

Using eleven two-year panels from MEPS, we examine how income changes impact out-of-pocket health care spending by single-mother families. There are four major findings that emerge from our study. First, we find that income losses lead to declines in single-mother families' out-of-pocket spending. Second, within the family, the spending on behalf of mothers falls more than spending for children. Third, we find that declines in out-of-pocket spending by single mothers with no diagnosed chronic condition are driving the declines in maternal out-of-pocket spending. Fourth, we find that in response to an income loss, mothers with diagnosed chronic conditions are driving increases in out-of-pocket spending toward prescription medications observed for some income loss subgroups.
To interpret these findings, it is critically important to understand the underlying mechanisms linking income losses and reduced out-of-pocket spending. Income losses can have adverse impact on single-mother families' ability to pay for care thereby causing these families to decrease their out-of-pocket spending. Families can reduce their outof-pocket spending in several ways which may or may not have adverse implications for their health.

In response to an income loss, single-mother families may seek cheaper care by choosing in-network rather than outof-network providers, opting for generic rather than brand name medications, or seeking help from patient assistance program sponsored by pharmaceutical companies. These measures may not necessarily compromise quality of care provided or the health status of single-mother family members. One of our findings indicates that there are reductions in out-of-pocket spending on emergency room care following income losses experienced by single-mother families. Emergency room services are often used by uninsured and underinsured as an alternative to primary health resulting in a large proportion of all emergency department visits being devoted to non-urgent conditions (Uscher-Pines et al., 2013). It is possible that in response to an income shock, singlemother families may seek to decrease their out-of-pocket spending by substituting more expensive emergency room care with less expensive office-based care. For non-urgent conditions this would not necessarily result in poorer health status. However, for urgent conditions such substitution may 
result in poorer health outcomes. From this standpoint, it is important to understand to what extent the increases in prescription medication spending among single-mothers with diagnosed chronic conditions may reflect declines in maternal health status versus substituting toward prescription medications and away from other types of treatments.

When experiencing an income loss, single-mother families may seek to reduce out-of-pocket spending in other ways that can potentially compromise family health status. Foregoing visits to health care providers, foregoing preventative care, discontinuing medications, or discontinuing other type of treatment would reduce out-of-pocket spending but may also result in reduced care quality and poorer health outcomes. By foregoing and delaying care at the time of income loss, single mother families face an increased risk of having undiagnosed and untreated chronic conditions. Note that our findings indicate that declines in maternal out-of-pocket spending are driven by single mothers with no diagnosed chronic condition which does not necessarily imply that these mothers do not have undiagnosed chronic condition. Undiagnosed chronic conditions present a widespread problem. For instance, nearly one-third of all diabetes cases, one fifth of all hypertension cases, and over a quarter of all elevated cholesterol cases are undiagnosed (Cowie et al., 2006; Mosca \& Kenny, 2014; Wilper, 2009). We find that single-mothers with no diagnosed chronic conditions decrease their out-of-pocket spending in response to an income loss not only toward emergency room care but also toward office-based visits and toward prescription medication spending. Forgoing and postponing care, particularly primary and preventative care, may not only delay the diagnoses and treatment of a chronic condition. It may also increase the likelihood of the onset of a chronic condition. In turn, undiagnosed or undertreated chronic conditions increase future risk of high-cost disabling complications.

Our study has several limitations. First, while we are able to account for changes in employment status within each year of the MEPS panel, we do not directly observe the instability of income within each year of the MEPS panel. We only observe the families' total annual income. Second, we do not separately account for families where single mothers experience multiple employment transition during a calendar year. There were only $3.6 \%$ of the families where single mothers both lost and gained employment during a calendar year. We account for multiple employment transitions by allowing employment variables not to be mutually exclusive. Finally, since our income category variables are defined once for each year in the panel, our estimates are necessarily symmetrical and provide the same magnitude of an effect for a loss or a gain in economic status.

Our study results imply that there is a need to further examine how income losses affect health care decisions of single mothers and their families. Our results show consistent evidence of decreased out-of-pocket spending by single-mother families in response to an income shock, particularly among single mothers with no diagnosed chronic conditions. More research is needed to understand whether and to what degree income losses may contribute to having undiagnosed and untreated chronic conditions among single mothers and other family members. With nearly a third of all families with children currently headed by single mothers, and with these families at an elevated risk of experiencing an income loss, we need to understand to what extent these income losses compromise the health of single-mother families.

Acknowledgements This research was funded by a grant from the Agency for Healthcare Research and Quality (AHRQ R01HS024053). We thank Samuel Zuvekas and Steven Hill of AHRQ for their expert advice on the use of MEPS data and development of longitudinal family weights.

\section{Declarations}

Conflict of interest The authors have no conflicts of interest to disclose.

\section{References}

Abramowitz, J. (2020). The effect of ACA state Medicaid expansions on medical out-of-pocket expenditures. Medical Care Research and Review, 77(1), 19-33. https://doi.org/10.1177/1077558718 768895

AHRQ. (2016). Using appropriate price indices for analysis of health care expenditures or income across multiple years. Agency for Healthcare Research and Quality, Rockville, MD. https://meps. ahrq.gov/about_meps/Price_Index.shtml

Anderson, K. E., McGinty, E. E., Presskreischer, R., \& Barry, C. L. (2021). Reports of forgone medical care among US adults during the initial phase of the COVID-19 pandemic. JAMA Network Open, 4(1), e2034882-e2034882. https://doi.org/10.1001/jaman etworkopen.2020.34882

Barardehi, I. H., Babiarz, P., \& Mauldin, T. (2020). Child support, consumption, and labor supply decisions of single-mother families. Journal of Family and Economic Issues, 41(3), 530-541. https:// doi.org/10.1007/s10834-020-09690-Z

Bzostek, S. H., \& Beck, A. N. (2011). Familial instability and young children's physical health. Social Science \& Medicine, 73(2), 282-292. https://doi.org/10.1016/j.socscimed.2011.04.014

Census Bureau. (2019). America's families and living arrangements: 2019. Census Bureau. Retrieved July 30 from https://www.census. gov/data/tables/2019/demo/families/cps-2019.html

Chamberlain, G. (1980). Analysis of covariance with qualitative data. Review of Economic Studies, 47(1), 225-238. https://doi.org/10. 2307/2297110

Cowie, C. C., Rust, K. F., Byrd-Holt, D. D., Eberhardt, M. S., Flegal, K. M., Engelgau, M. M., Saydah, S. H., Williams, D. E., Geiss, L. S., \& Gregg, E. W. (2006). Prevalence of diabetes and impaired fasting glucose in adults in the U.S. population: National health and nutrition examination survey 1999-2002. Epidemiology, 29(6), 1263-1268. https://doi.org/10.2337/dc06-0062 
Ganong, P., \& Noel, P. (2019). Consumer spending during unemployment: Positive and normative implications. American Economic Review, 109(7), 2383-2424. https://doi.org/10.1257/aer.20170537

Golberstein, E., \& Gonzales, G. (2015). The effects of Medicaid eligibility on mental health services and out-of-pocket spending for mental health services. Health Services Research, 50(6), 17341750. https://doi.org/10.1111/1475-6773.12399

Grafova, I. B., Monheit, A. C., \& Kumar, R. (2020a). How do changes in income, employment and health insurance affect family mental health spending? Review of Economics of the Household, 18(1), 239-263. https://doi.org/10.1007/s11150-018-9436-y

Grafova, I. B., Monheit, A. C., \& Kumar, R. (2020b). How do economic shocks affect family health care spending burdens? Journal of Family and Economic Issues. https://doi.org/10.1007/ s10834-020-09681-0

Hackney, D., Friesner, D., \& Johnson, E. (2018). Towards a working profile of medical bankruptcy. Journal of Financial Counseling and Planning, 29, 75-90. https://doi.org/10.1891/1052-3073.29.1. 75

Hayes, J., \& Hartman, H. (2011). Women and men living on the edge: Economic insecurity after the great recession. Institute for Women's Policy Research, Washington, DC. https://iwpr.org/publicatio ns/women-and-men-living-on-the-edge-economic-insecurityafter-the-great-recession/

Henry J. Kaiser Family Foundation. (2020). Women's health insurance coverage. Women's Health Policy Program, Kaiser Family Foundation, Menlo Park, CA. https://www.kff.org/womens-healthpolicy/fact-sheet/womens-health-insurance-coverage-fact-sheet/\# footnote-446031-6

Himmelstein, D. U., Lawless, R. M., Thorne, D., Foohey, P., \& Woolhandler, S. (2019). Medical bankruptcy: Still common despite the affordable care act. American Journal of Public Health, 109(3), 431-433. https://doi.org/10.2105/ajph.2018.304901

Irvin, K., Fahim, F., Alshehri, S., \& Kitsantas, P. (2018). Family structure and children's unmet health-care needs. Journal of Child Health Care, 22(1), 57-67. https://doi.org/10.1177/1367493517 748372

Karaca-Mandic, P., Choi-Yoo, S. J., Lee, J., \& Scal, P. (2014). Family out-of-pocket health care burden and children's unmet needs or delayed health care. Academic Pediatrics, 14(1), 101-108. https:// doi.org/10.1016/j.acap.2013.10.005

Karaca-Mandic, P., Choi Yoo, S. J., \& Sommers, B. D. (2013). Recession led to a decline in out-of-pocket spending for children with special health care needs. Health Affairs, 32(6), 1054-1062. https://doi.org/10.1377/hlthaff.2012.1137

Kirzinger, A., Muñana, C., Wu, B., \& Brodie, M. (2019). Data note: Americans' challenges with health care costs. California: Kaiser Family Foundation.

Kwon, E., Park, S., \& McBride, T. D. (2018). Health insurance and poverty in trajectories of out-of-pocket expenditure among lowincome middle-aged adults. Health Services Research, 53(6), 4332-4352. https://doi.org/10.1111/1475-6773.12974

Langton, C. E., \& Berger, L. M. (2011). Family structure and adolescent physical health, behavior, and emotional well-being. Social Service Review, 85(3), 323-357. https://doi.org/10.1086/661922

McCarthy-Alfano, M., Glickman, A., Wikelius, K., \& Weiner, J. (2019). Measuring the burden of health care costs for working families. Health Affairs Blog. https://doi.org/10.1377/hblog20190 327.999531. Accessed 18 June 2020.

Monheit, A. C., Grafova, I. B., \& Kumar, R. (2020). How does family health care use respond to economic shocks? realized and anticipated effects. Review of Economics of the Household, 18(2), 307-334. https://doi.org/10.1007/s11150-018-9438-9

Mosca, I., \& Kenny, R. A. (2014). Exploring differences in prevalence of diagnosed, measured and undiagnosed hypertension: The case of Ireland and the United States of America. International
Journal of Public Health, 59(5), 759-767. https://doi.org/10.1007/ s00038-014-0573-7

Mundlak, Y. (1978). On the pooling of time series and cross section data. Econometrica, 46(1), 69-85. https://doi.org/10.2307/19136 46

Papke, L. E., \& Wooldridge, J. M. (2008). Panel data methods for fractional response variables with an application to test pass rates. Journal of Econometrics, 145(1), 121-133. https://doi.org/10. 1016/j.jeconom.2008.05.009

Park, R. E. (1966). Estimation with heteroscedastic error terms. Econometrica, 34(4), 888.

Parker, K., Minkin, R., \& Bennett, J. (2020). Economic fallout from COVID-19 continues to hit lower-icome Americans the hardest. Pew Research Center. https://www.pewsocialtrends.org/wp-conte nt/uploads/sites/3/2020/09/SDT_2020.09.24_COVID-19-Perso nal-Finances_FINAL.update2.pdf

Semega, J., Kollar, M., Creamer, J., \& Mohanty, A. (2020). Income and poverty in the United States: 2018 Current Population Report P60-266(RV), Census Bureau, U.S. Government Printing Office.

Shaefer, H. L., Grogan, C. M., \& Pollack, H. A. (2011). Transitions from private to public health coverage among children: Estimating effects on out-of-pocket medical costs and health insurance premium costs. Health Services Research, 46(3), 840-858. https:// doi.org/10.1111/j.1475-6773.2010.01238.x

Shin, S., \& Kim, H. (2018). Health trajectories of older Americans and medical expenses: Evidence from the health and retirement study data over the 18 year period. Journal of Family and Economic Issues, 39(1), 19-33. https://doi.org/10.1007/s10834-017-9542-7

Uscher-Pines, L., Pines, J., Kellermann, A., Gillen, E., \& Mehrotra, A. (2013). Emergency department visits for nonurgent conditions: Systematic literature review. American Journal of Managed Care, 19(1), 47-59. https://pubmed.ncbi.nlm.nih.gov/23379744

Valluri, S., Mammen, S., \& Lass, D. (2015). Health care use among rural, low-income women and children: Results from a 2-stage negative binomial model. Journal of Family and Economic Issues, 36(1), 154-164. https://doi.org/10.1007/s10834-014-9424-1

Wilper, A. P., Woolhandler, S., Lasser, K. E., McCormick, D., Bor, D. H., \& Himmelstein, D. U. (2009). Hypertension, diabetes, and elevated cholesterol among insured and uninsured U.S. adults. Health Affairs, 28(Supplement 1), w1151-w1159. https://doi.org/ 10.1377/hlthaff.28.6.w1151

Wooldridge, J. M. (2019). Correlated random effects models with unbalanced panels. Journal of Econometrics, 211(1), 137-150. https://doi.org/10.1016/j.jeconom.2018.12.010

Zan, H., \& Scharff, R. L. (2018). The effects of children's health on mothers' employment. Journal of Family and Economic Issues, 39(2), 297-309. https://doi.org/10.1007/s10834-017-9552-5

Publisher's Note Springer Nature remains neutral with regard to jurisdictional claims in published maps and institutional affiliations.

Irina B. Grafova received Ph.D. in Economics from the University of Michigan Ann Arbor in 2005. She currently works as assistant professor at the Department of Health Behaviors, Society, and Policy at Rutgers School of Public Health. Her current research interest include the socio-economic determinants of health, financial toxicity of cancer, health policy, and health care spending.

Alan C. Monheit is Professor of Health Economics in the Department of Health Behavior, Society, and Policy at the Rutgers University School of Public Health. He holds a doctorate in economics from the Graduate Center, City University of New York. Professor Monheit is also a research associate in health economics at the National Bureau of Economic Research, and a Research Professor at the Rutgers Center for 
State Health Policy. His research focuses on family health care decision making, health reform, health insurance, health care spending, and social determinants of health.

Rizie Kumar received M.A. in Applied Demography from Georgetown University in 1992. She works as Statistical Analyst in the Department of Sociology at the University of Maryland. Previously, she was employed at Rutgers University where she worked in the School of Public Health for 15 years. She has extensive experience working with large data sets using SAS/STATA. Her research interest include health services research and policy analysis. 